ARTIGO

Recebido em: 28/04/2017

Aceito em: 09/04/2018

\section{Levantamento, catalogação e digitalização de fontes históricas sobre as Cataratas do Iguaçu (1850-1910)}

\author{
Survey, cataloging and digitalization of historical sources about the \\ Iguaçu Falls (1850-1910)
}

\author{
Cezar KARPINSKI (cezark@hotmail.com)* \\ Genilson GERALDO (genilsongeraldo.biblio@gmail.com)** \\ Marçal Quevedo de SOUZA (marcalufsc@gmail.com)** \\ Sabrina MARTINS (sabrinafoco@gmail.com) ${ }^{* *}$ \\ * Professor da Universidade Federal de Santa Catarina - UFSC. \\ ** Discente do curso de Biblioteconomia da da Universidade Federal de Santa Catarina - UFSC.
}

\section{Resumo}

Apresentam-se as atividades desenvolvidas pelo Projeto de Pesquisa e Iniciação Científica "A construção de uma 'maravilha': Brasil e Argentina e as disputas pela paisagem das Cataratas do Iguaçu (1850-1910)" entre 12 de dezembro de 2013 e 31 de dezembro de 2016. Um dos objetivos desta pesquisa foi o de buscar fontes históricas sobre as Cataratas do Iguaçu durante o recorte temporal proposto pelo projeto. Com esta delimitação, fez-se o levantamento, a catalogação e a digitalização, por meio de fotografia digital, de documentos preservados e disponíveis em unidades de informação do Brasil e da Argentina. A metodologia da pesquisa foi dividida em três etapas, a primeira consistiu na seleção das bibliotecas e dos arquivos nacionais que disponibilizam catálogos em sistemas web, realizando assim o levantamento das referências e sua instituição de guarda. A segunda etapa consistiu na pesquisa in loco, com o acesso e digitalização das obras. E, por fim, formou-se um acervo digital. 0 resultado é a constituição de um acervo que conta com 138 fontes históricas catalogadas, das quais foram fotografadas 71 que, juntas, perfazem um total de 2091 imagens contendo informações sobre a história da paisagem, da interação dos habitantes locais com o meio ambiente e das relações internacionais entre Brasil e Argentina.

Palavras-chave: Pesquisa e Desenvolvimento. Fontes de Informação. Patrimônio Documental. Digitalização. Interdisciplinaridade.

\begin{abstract}
In this study, the activities developed by the Research and Scientific Initiation Project "The construction of a 'wonder': Brazil and Argentina and the disputes over the landscape of the Iguaçu Falls (1850-1910)" between December 12, 2013 and December 31, 2016 are presented. One of the objectives of this research was to search for historical sources about the Iguaçu Falls during the temporal cut proposed by the project. With this delimitation, the collection, cataloging and digitalization of documents preserved and available in information units in Brazil and Argentina were done through digital photography. The research methodology was divided into three stages. The first one consisted in the selection of national libraries and archives that make catalogs available on web systems, thus carrying out the survey of references and their guard institution. The second stage consisted of on-site research, with the access and digitization of the works. And, finally, a digital collection was formed. As a result, there is the constitution of a collection that has 138 cataloged historical sources, of which 71 were photographed. All of them together make up a total of 2,091 images containing the history of the landscape, the interaction of the local inhabitants with the environment and the relations Between Brazil and Argentina.
\end{abstract}

Keywords: Research and Development. Information Sources. Documentary Heritage. Digitization. Interdisciplinary.

v. 23, n. esp., 2018 p. $99-111$

ISSN 1518-2924 


\section{INTRODUÇão}

Este artigo apresenta as atividades do Projeto de Pesquisa e Iniciação Científica "A construção de uma 'maravilha': Brasil e Argentina e as disputas pela paisagem das Cataratas do Iguaçu (1850-1910)" desenvolvidas entre 12 de dezembro de 2013 e 31 de dezembro de 2016. A temática e as atividades foram concebidas de forma interdisciplinar entre a História e a Ciência da Informação. $O$ intuito deste diálogo foi o de alcançar um resultado útil ao crescimento científico das duas áreas do conhecimento. Sendo assim, o objetivo geral foi o de "buscar, catalogar e digitalizar, por meio de fotografia digital, fontes históricas sobre as cataratas do Iguaçu no período de 1850 e 1910, em unidades de informação brasileiras e argentinas".

Já os objetivos específicos foram definidos para subsidiar respostas às várias perguntas que envolveram o projeto: Onde encontrar documentação sobre os limites entre Brasil e Argentina nas Cataratas do Iguaçu? Os conflitos que envolveram os acordos de limites entre Brasil e Argentina estiveram presentes também na delimitação de limites da paisagem? É possível constituir acervos digitais sobre a temática? Estas e outras perguntas só poderiam ser respondidas com acesso à informação de fontes históricas do período, pois não se tinha acesso, até o momento, a referências bibliográficas que fornecessem tais dados.

Tendo isto como pressupostos, definiram-se os seguintes objetivos específicos: 01) Entender até que ponto as relações em torno do domínio pela paisagem das Cataratas do Iguaçu colaboram para os acordos de limites e fronteiras entre Brasil e Argentina; 02) Historiar as relações entre militares brasileiros e representantes do governo argentino em fins do Século XIX e início do XX na Colônia Militar da foz do Iguaçu; 03) Intercambiar documentos históricos sobre a temática em questão com países vizinhos, especialmente a Argentina; 04) Formar, primeiramente, um acervo digital sobre os objetos Parque Nacional e Cataratas do Iguaçu.

0 fator crucial para o sucesso da pesquisa foi a participação da equipe executora num trabalho coletivo que agregou novos conhecimentos aos que já possuía cada participante. Especial destaque à participação de alunos de graduação na qualidade de pesquisadores iniciantes, com bolsa ou voluntariamente, que fizeram da pesquisa uma oportunidade para a prática disciplinar. Ao todo foram oito estudantes de Iniciação Científica de quatro cursos de graduação: Biblioteconomia, História, Relações Internacionais e Sociologia de duas universidades distintas - a Universidade Federal da Integração Latino-americana (UNILA) e a Universidade Federal de Santa Catarina (UFSC), conforme detalha o Quadro 1.

Quadro 1: Discentes de iniciação científica no projeto

\begin{tabular}{lllc}
\hline \multicolumn{1}{c}{ DISCENTE } & \multicolumn{1}{c}{ CURSO } & \multicolumn{1}{c}{ IFES } & \multicolumn{1}{c}{ PERÍODO } \\
\hline Daniela Ivanna Galli-Mattiauda & Relações Internacionais & UNILA & $01 / 01 / 2014$ à 31/12/2015 \\
Mariana Rodrígues-Espinosa & Ciência Política & UNILA & $01 / 01 / 2014$ à 31/12/2015 \\
Rejane Anahi Camilo Ruiz & História & UNILA & $01 / 01 / 2014$ à 31/12/2015 \\
Genilson Geraldo & Biblioteconomia & UFSC & $01 / 12 / 2015$ à 31/12/2016 \\
Marçal Quevedo de Souza & Biblioteconomia & UFSC & $01 / 12 / 2015$ à 31/12/2016 \\
Sabrina Martins & Biblioteconomia & UFSC & $01 / 12 / 2015$ à 31/12/2016 \\
Eliana Jackeline Alvarez-Muñoz & Ciência Política & UNILA & $01 / 01 / 2016$ à 31/12/2016 \\
José Damian Torko-Gómez & Relações Internacionais & UNILA & $01 / 01 / 2016$ à 31/12/2016 \\
\hline
\end{tabular}

Fonte: Karpinski (2017a).

Como resultados aponta-se a formação do catálogo de 138 obras e do acervo digital de 2.153 imagens contendo informações de grande potencial produtivo para a área de História, principalmente. Foram escritos cinco artigos (contando com este), 
sendo que quatro já se encontram publicados e um em fase de avaliação na submissão. Em anais de evento científico publicou-se um trabalho completo, um resumo expandido e um resumo. É importante computar também como resultado a orientação de nove planos de trabalhos de Iniciação Científica o que, para o coordenador do projeto, fez da pesquisa uma boa oportunidade para formação de futuros pesquisadores e estudantes de pós-graduação.

\section{DESENVOLVIMENTO}

Primeiramente, buscaram-se definições sobre os conceitos de limites e de fronteiras para articulá-los à pesquisa prática. Como o objeto de estudo está entre dois países latino-americanos, optou-se por autores latino-americanos que, de algum modo, estabelecessem parâmetros para conceituação nesta parte do continente. Nesse sentido, chegou-se a Aguirre, Mendieta e Careta (2008) que coordenaram a obra Estudios regionales y de fronteras interiores discutindo os conceitos de "região", "limite" e "fronteira" na América Latina. Para estes autores, de um modo geral, o termo fronteira possui uma função ampla e se refere geralmente a uma região, em contrapartida, o termo limite tem se referido a uma concepção precisa, linear e definida no espaço. Contudo, para os autores, essas definições, embora usuais, não afastam as discussões e questionamentos, uma vez que o conceito de fronteira possui uma ampla carga semântica que pode variar com o tempo.

Deste modo, é possível perceber a dificuldade de delimitar ou até mesmo conceituar o que é fronteira, limite ou até mesmo o domínio, fato que se reflete em várias das fontes históricas catalogadas na pesquisa. Principalmente quando existe uma disputa na qual está atrelada interesses políticos, econômicos e ideológicos, como foi o caso da disputa territorial que envolveu Brasil e Argentina no período em que se formou a maior parte da documentação catalogada. Como especialistas em estudos regionais e de fronteiras latino-americanos, Aguirre, Mendieta e Careta (2008, p.5-6) corroboram com as constatações desta pesquisa ao afirmar que uma fronteira não é uma linha arbitrária feita em um mapa. Para eles, este termo é forjado a partir de uma estrutura ideológico-política funcional e completa, que reflete na superfície da terra e se deixa firmar em título de propriedade ou em tratado territorial entre as nações.

Sendo assim, é possível afirmar que a fronteira político-territorial é um espaço de ações beligerantes e, por isso, não houve como se afastar desta realidade quando se tratou de analisar os documentos catalogados. Não seria exagero afirmar que a grande massa documental produzida no recorte temporal desta pesquisa se deu, justamente, devido a esta especificidade. Desde as dificuldades de obediência ao Tratado de Tordesilhas firmado entre as duas nações colonizadoras em 1494 e demais acordos frustrados entre Espanha e Portugal, os dois países latino-americanos seguiram disputando territórios até o início do Século XX. Tais conflitos, primeiramente armados no tempo em que eram colônias e posteriormente discursivo e político como países independentes, se fazem presentes na documentação catalogada e dão singularidade aos debates acerca dos recursos naturais, paisagem e memória da região em disputa.

Esta nuance entre conceitos teóricos, contexto histórico e a prática de pesquisa orientada contribuiu para uma melhor compreensão acerca do material pesquisado nas unidades de informação. De um lado, os documentos históricos em diversos formatos, suportes e estado de conservação que mereciam o olhar técnico para construção de catálogos e metodologias para representação da informação e organização do conhecimento. Por outro lado, a instrumentalidade teórica e histórica fornecendo subsídios para compreensão do documento como um instrumento de memória, de 
história e de luta política. Essa relação entre o viés teórico-prático forneceu subsídios importantes para o desenvolvimento das atividades orientadas, possibilitando uma troca constante de conhecimento e crescimento acadêmico-científico. Como a maior parte da pesquisa de campo foi feita pelos pesquisadores de iniciação científica, entende-se que esta experiência aprofundou o papel da Iniciação Científica que é, segundo CNPq (2006), "Despertar vocação científica e incentivar talentos potenciais entre estudantes de graduação universitária, mediante participação em projeto de pesquisa, orientados por pesquisador qualificado".

Além de contribuir para o bom andamento e para o alcance dos objetivos da pesquisa, a iniciação científica desenvolvida ao longo do projeto proporcionou aos estudantes bolsistas e voluntários um melhor desempenho na graduação, na escrita voltada à comunicação científica e no estímulo à participação em programas de pósgraduação. Das três bolsistas graduadas até o momento, duas foram aprovadas para programas de pós-graduação no ano de 2015. Desta forma, a experiência deste projeto soma-se a de inúmeras constatações dos benefícios dos programas de iniciação científica das universidades brasileiras. Massi e Queiroz (2014), por exemplo, apresentam uma boa pesquisa sobre os principais aspectos positivos da Iniciação Científica na produção bibliográfica brasileira

Um dos principais resultados do levantamento e coleta de fontes históricas foi o acervo digital. No Brasil, a digitalização de documentação histórica tem crescido consideravelmente neste século, especialmente em arquivos e bibliotecas públicas. É um fenômeno que surge da necessidade de dar acesso ao mesmo tempo em que se preserva a informação incrustada em variados suportes. Desde o início, a proposta desta pesquisa foi a de construir um acervo digital com documentos sobre as cataratas do Iguaçu produzidos no recorte temporal da pesquisa. 0 objetivo deste acervo é o aproveitamento das fontes por outros pesquisadores.

Para tanto, a equipe desenvolveu planos de trabalhos específicos para o conhecimento teórico e prático na formação de acervo e de digitalização por máquina fotográfica. Foi imprescindível nesta fase teórica as reflexões de Levy (2001), especialmente no que se refere à "diferença" entre atualidade e virtualidade e suas reverberações nas possibilidades digitais do mundo contemporâneo, em grande parte apoiadas no pensamento de Deleuze (1968).

Do ponto de vista prático, embora não haja uma normalização específica para este tipo de digitalização, aceitaram-se, guardadas as devidas distinções, as recomendações do CONARQ (2010), no que concerne ao uso de câmeras digitais. Embora este documento esteja voltado aos profissionais da área e às instituições de guarda e preservação de acervos raros, foi escolhido como parâmetro para as atividades desta pesquisa com as devidas adaptações metodológicas.

\subsection{Metodologia}

Pesquisa exploratória e documental que consistiu no levantamento, catalogação e digitalização de fontes de informação sobre as Cataratas do Iguaçu produzidas entre os anos de 1850 e 1920. Para o levantamento, foram selecionadas bibliotecas e arquivos nacionais do Brasil e da Argentina, além das instituições estaduais de informação e memória do Estado do Paraná. O primeiro recorte para seleção das unidades de informação a serem pesquisadas foi o da existência de sistemas de busca on line do seu acervo. Desta forma, chegou-se ao número de três instituições paranaenses, o mesmo número de argentinas e seis instituições nacionais brasileiras, conforme detalha o Quadro 2. 
Quadro 2: Unidades de informação selecionadas para a pesquisa

\begin{tabular}{clc}
\hline LOCAL & \multicolumn{1}{c}{ UNIDADE DE INFORMAÇÃo } & SIGLA \\
\hline \multirow{2}{*}{ BUENOS AIRES } & Biblioteca del Congreso de la Nación & BNCON \\
& Biblioteca Nacional de Maestros & BNMAE \\
& Biblioteca Nacional Mariano Moreno & BNMAMO \\
\hline \multirow{2}{*}{ CURITIBA } & Biblioteca Pública do Paraná & BPP \\
& Instituto Histórico e Geográfico do Paraná & IHGP \\
& Museu Paranaense & MP \\
\hline \multirow{3}{*}{ RIO DE JANEIRO } & Arquivo Histórico do Exército do Rio de Janeiro & AHE \\
& Arquivo Histórico do Itamaraty & AHI \\
& Arquivo Nacional & AN \\
& Biblioteca da Marinha & BM \\
& Biblioteca Nacional & BN \\
& Instituto Histórico e Geográfico Brasileiro & IHGB \\
\hline
\end{tabular}

Fonte: Karpinski (2017a).

Depois de selecionadas as instituições, passou-se a definição dos termos de busca que se restringiram aos termos "Iguaçu" (e suas variáveis "Iguazú", "Iguassu" e "Iguassú") e "Cataratas do Iguaçu" (com as mesmas variáveis). Primeiramente fez-se com o filtro "data inicial" e "data final" de publicação, estabelecendo 1850 e 1920, respectivamente. Em seguida, fez a mesma busca sem o filtro de datas, com o objetivo de levantar documentos sem data de publicação. A consulta foi efetuada nos módulos "monografias", "mapas", "periódicos" e "audiovisual", sendo que todos os documentos recuperados foram verificados individualmente e descartados aqueles que não se relacionavam ao escopo da pesquisa. Para cada instituição, criaram-se tabelas de acordo com o tipo de documento e com as seguintes especificações: autor, título, data, código de classificação ou descrição, no de registro e localização.

Feito o levantamento, passou-se para a segunda fase do projeto que consistiu na pesquisa in loco, para a análise e seleção documental. Nesta etapa, todas as referências levantadas na internet foram solicitadas junto às bibliotecas e arquivos que, de acordo com a disponibilidade e política institucional, forneciam para a análise. Uma vez constatada a sua relevância, o documento foi catalogado e fotografado digitalmente, no todo ou em partes específicas, de acordo com os termos de autorização de autorização de cada instituição. 0 processo de digitalização por meio de fotografia não foi o mesmo em todas as instituições e documentos. Contudo, para este trabalho utilizou-se a câmera fotográfica Cânon Power Shot S100 Digital 12.1MP sensitive $24 \mathrm{~mm}$ wide $5 \mathrm{x}$ e foi imprescindível a contribuição de CONARQ (2010). Para captura da imagem estabeleceram-se os seguintes parâmetros: todas as imagens foram geradas no tamanho de 12 MP, Sem Flash, ISO variável com o ambiente (em geral entre 3200 e 6400) e a distância da câmera e do documento também variável entre 30 e $50 \mathrm{~cm}$.

A terceira fase da pesquisa foi a de tratamento das imagens e confecção de um catálogo temático das fontes de informação sobre as Cataratas do Iguaçu no período de 1850 e 1920, disponíveis nas instituições pesquisadas. Nesta etapa, todas as imagens capturadas durante o processo de digitalização por fotografia digital foram tratadas. 
Como não existe uma normalização específica para este tipo de digitalização, cuja principal característica é a funcionalidade, a equipe estabeleceu os seguintes parâmetros: 300 dpi, 8 a 12 Megapixel, 24 bpp e extensão de arquivo JPEG.

0 catálogo foi elaborado de forma bastante simples, obedecendo ao princípio de "uso comum" onde "O vocabulário usado na descrição e nos pontos de acesso deve estar de acordo com o da maioria dos utilizadores (usuários)" (IFLA, 2009, p.2). Como a maioria dos utilizadores deste tipo de informação são historiadores, utilizou-se um vocabulário comum ao que é necessário citar das fontes históricas que comumente se refere especificamente à autor, título, local e data.

É importante salientar que todos os procedimentos da pesquisa foram desenvolvidos a partir de um plano de trabalho criado para cada atividade e equipe, o que permitiu a otimização dos recursos financeiros e humanos. Pode-se dizer que este método de atividade orientada possibilitou aprofundar discussões teóricas disciplinares a partir de uma prática de pesquisa interdisciplinar. Pelo Quadro 3, exemplifica-se esse recurso metodológico aplicados aos discentes de Biblioteconomia.

Quadro 3: Orientação aplicada por planos de trabalho

\begin{tabular}{|c|c|c|}
\hline PLANO DE TRABALHO & DISCENTES & META ALCANÇADA \\
\hline $\begin{array}{l}\text { 1. Normalização e digitalização de fontes } \\
\text { históricas. }\end{array}$ & Genilson Geraldo & $\begin{array}{l}\text { Definição das metodologias de captura e } \\
\text { tratamento das imagens digitais. }\end{array}$ \\
\hline $\begin{array}{l}\text { 2. Direitos autorais na legislação de Brasil e } \\
\text { Argentina para aplicabilidade em } \\
\text { publicações de } 1850 \text { a } 1920 \text {. }\end{array}$ & Marçal Souza & $\begin{array}{l}\text { Segurança jurídica na digitalização e } \\
\text { disponibilização do acervo digital do } \\
\text { projeto. }\end{array}$ \\
\hline 3. Normas de indexação de fontes históricas. & Sabrina Martins & $\begin{array}{l}\text { Instrumento de indexação especifico para } \\
\text { as fontes históricas e usuários do projeto. }\end{array}$ \\
\hline $\begin{array}{l}\text { 4. Levantamento, catalogação e digitalização } \\
\text { de documentação histórica em } \\
\text { Curitiba/PR. }\end{array}$ & $\begin{array}{l}\text { Genilson Geraldo } \\
\text { e Marçal Souza }\end{array}$ & Catálogo e Acervo digital. \\
\hline $\begin{array}{l}\text { 5. Levantamento, catalogação e digitalização } \\
\text { de documentação histórica no Rio de } \\
\text { Janeiro/RJ }\end{array}$ & Sabrina Martins & Catálogo e Acervo digital. \\
\hline
\end{tabular}

Fonte: Karpinski (2017a).

\section{RESULTADOS}

Após o levantamento e análise in loco das obras, chegou-se a um total de 138 documentos catalogados, dos quais 71 foram digitalizados (no todo ou em parte) que juntos perfizeram um total de 2091 imagens digitais tratadas de acordo com a metodologia supracitada. Os idiomas variam entre o espanhol, francês, italiano e português e a tipologia documental é variada. A Tabela 1 mostra os dados quantitativos do catálogo e do acervo digital de acordo com os tipos de documentos.

Tabela 1: Quantitativo do acervo

\begin{tabular}{lclcc}
\hline \multicolumn{1}{c}{ TIPO DE DOCUMENTO } & QTD. & \multicolumn{1}{c}{ IDIOMA } & DIG. & IMA. \\
\hline Relatos de viajantes - RV & 20 & Esp., Ita., Por. & 18 & 1187 \\
Relatórios Oficiais - RO & 14 & Esp., Por., Ing. & 04 & 605 \\
Álbum fotográfico - AB & 02 & Esp., Por. & 02 & 37 \\
Poesias - PO & 01 & Esp. & 01 & 17 \\
Plantas - PL & 05 & Por. & 03 & 03 \\
Mapas - MP & 40 & Esp., Por. & 25 & 105
\end{tabular}




\begin{tabular}{lrlrr} 
Correspondências - CO & 05 & Por. & 02 & 28 \\
Projetos - PJ & 03 & Esp., Por., Fra. & 01 & 49 \\
Cartões Postais & 40 & Esp. & 40 & 40 \\
Pinturas de Paisagem & 08 & Esp., Por. & 08 & 08 \\
\hline TOTAL & $\mathbf{1 3 8}$ & & $\mathbf{7 1}$ & $\mathbf{2 0 9 1}$ \\
\hline
\end{tabular}

Fonte: Dados da pesquisa.

0 volume documental varia no decorrer das décadas, obedecendo também às variantes relacionadas à logística, técnicas e contexto histórico. Os cartões postais, por exemplo, embora sendo um documento cuja quantidade surpreende, só começam a aparecer no início do século XX. Conforme Figura 1, a data do primeiro cartão catalogado se refere ao Réveillon de 1901 e advém de uma prática já comum na Europa finessecular (SCHAPOCHNIK, 2006; MASOTTA (2007). Já as pinturas de paisagem, mesmo sendo em número bem menor constituem documentos singulares, pois são as primeiras obras de divulgação das Cataratas do Iguaçu no exterior. Pelo menos duas das obras encontradas foram pintadas sob encomenda do governo argentino para representar a paisagem do país na Exposição Universal de Chicago em 1893 (Figura 2).

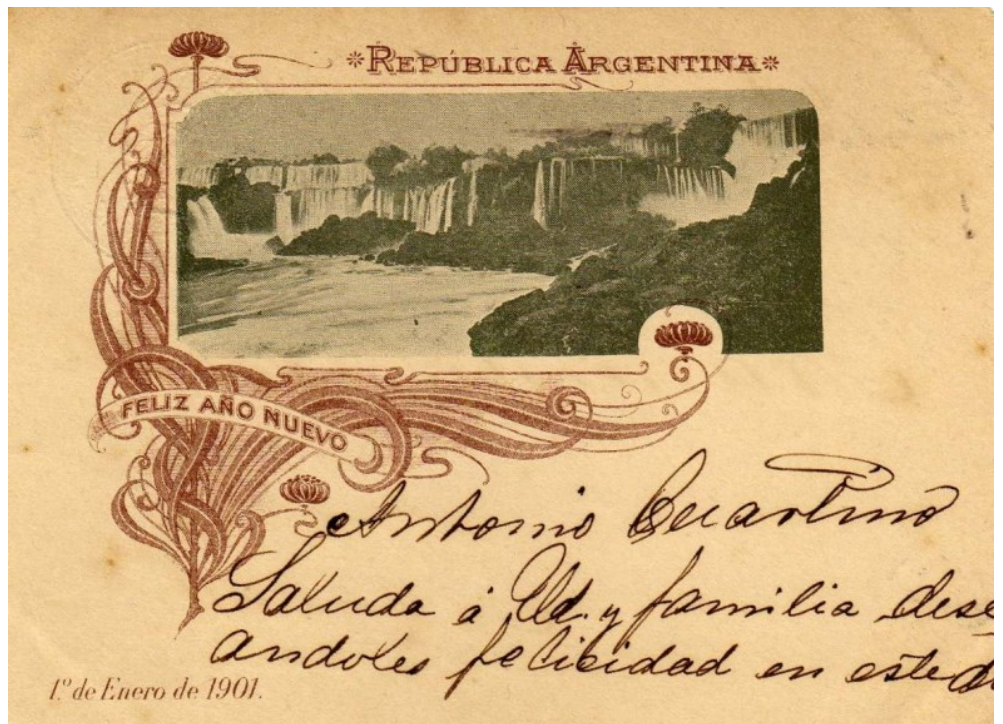

Figura 1: Cartão Postal alusivo ao Réveillon de 1901

Fonte: República Argentina, [1901].

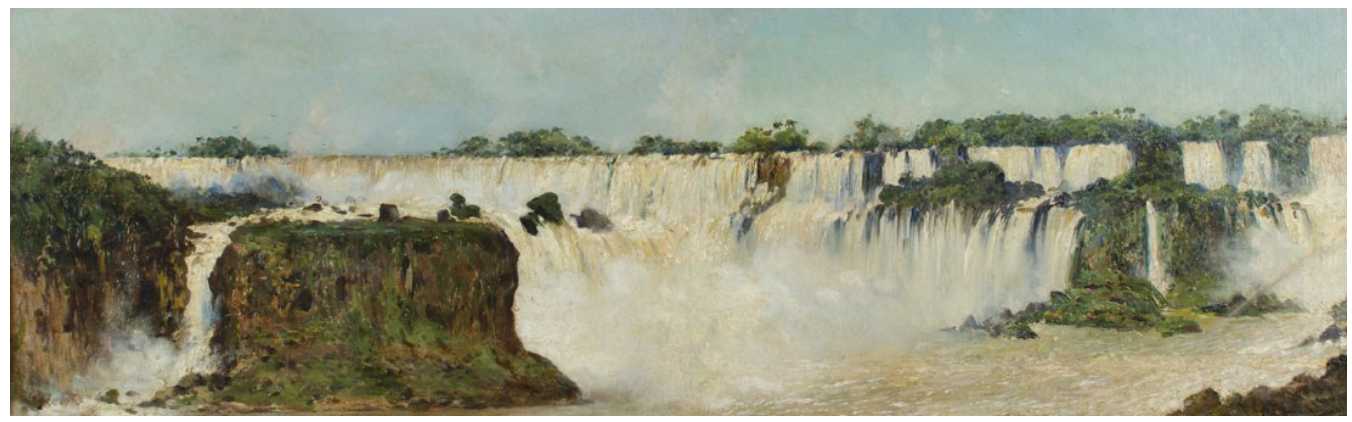

Figura 2: Quadro "Cascata del Iguazu"

Fonte: Ballerini (1892). 
Os mapas também representam uma parcela significativa do quantitativo documental, também somando um total de 40 títulos. Em termos qualitativos, é uma das fontes que, juntamente com os Relatórios de Viagens, detalha o território em litígio, destacando os recursos naturais e as parcas possibilidades logísticas do território. Além disso, vários mapas foram confeccionados por comissões mistas, compostas por brasileiros e argentinos, obedecendo a Acordos Internacionais para estudos e definição de limites e fronteiras. 0 contexto de busca de uma solução para os seculares problemas acerca dos limites entre Brasil e Argentina na região das Cataratas do Iguaçu se reflete no volume de publicações catalogadas. Do material catalogado, cerca de 98 títulos (quase $70 \%$ do catálogo) foram publicados entre os anos de 1880 e 1909, auge das discussões e conflitos sobre os limites no território em litígio. Os dados quantitativos por ano de publicação se encontram no Quadro 4 e corroboram com a discussão acima.

Quadro 4: Documentos por década de publicação

\begin{tabular}{l|ccccccc}
\hline \multicolumn{1}{c}{ DOCUMENTOS } & \multicolumn{7}{c}{ DÉCADA DE PUBLICAÇÃO } \\
\cline { 2 - 8 } & 1850 & 1860 & 1870 & 1880 & 1890 & 1900 & 1910 \\
\hline Relatos de viajantes - RV & & & & 4 & 9 & 4 & 3 \\
Relatórios Oficiais - RO & 1 & 3 & 1 & 3 & 3 & & 3 \\
Álbum fotográfico - AB & & & & & & 2 & \\
Poesias - PO & & & & & & 1 & \\
Plantas - PL & 2 & & & 1 & 1 & & 1 \\
Mapas - MP & 11 & & & 4 & & 20 & 5 \\
Correspondências - CO & 1 & & & & 1 & 2 & 1 \\
Projetos - PJ & 2 & & & & & & 1 \\
Cartões Postais & & & & & 2 & 35 & 3 \\
Pinturas de Paisagem & & & & & 6 & & 2 \\
\hline TOTAL & $\mathbf{1 7}$ & $\mathbf{3}$ & $\mathbf{1}$ & $\mathbf{1 2}$ & $\mathbf{2 2}$ & $\mathbf{6 4}$ & $\mathbf{1 9}$ \\
\hline
\end{tabular}

Fonte: Dados da pesquisa.

As instituições que mais se destacam na preservação e acesso das obras são a Biblioteca Pública do Paraná (Curitiba) e a Biblioteca Nacional Mariano Moreno (Buenos Aires). A Tabela 2 apresenta, também de forma quantitativa, a distribuição de obras por unidade de informação, exceto as pinturas de paisagem e os cartões postais, pois nem todos fazem parte do seu acervo. As primeiras por pertencerem a pessoas físicas, a museus, galerias e prédios públicos, já os cartões postais, embora também sejam encontrados em sessões iconográficas de algumas instituições, em sua maioria, fazem parte de coleções particulares. 
Tabela 2: Distribuição das obras por instituição

\begin{tabular}{|c|c|c|c|c|c|c|c|c|c|c|}
\hline LOCAL & UI & RV & RO & AB & PO & PL & MP & $\mathrm{CO}$ & PJ & Total/Ins. \\
\hline \multirow{4}{*}{ 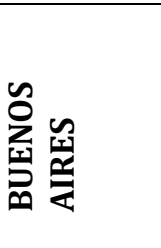 } & BNCON & - & 03 & - & - & - & - & - & - & 03 \\
\hline & BNMAE & 01 & - & - & - & - & 13 & 01 & - & 15 \\
\hline & BNMAMO & 12 & 01 & 01 & 01 & 01 & 8 & - & 01 & 25 \\
\hline & BPP & 04 & - & - & - & - & - & - & - & 04 \\
\hline \multirow{4}{*}{ 吕 } & IHGP & 01 & - & - & - & - & - & 01 & - & 02 \\
\hline & MP & - & - & - & - & - & 01 & - & - & 01 \\
\hline & AHE & - & - & - & - & 02 & 06 & - & - & 08 \\
\hline & AHI & - & 02 & - & - & - & 04 & - & 01 & 07 \\
\hline \multirow{4}{*}{ 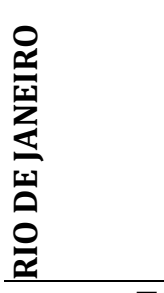 } & AN & - & 02 & - & - & 02 & 04 & 02 & - & 10 \\
\hline & BM & - & - & - & - & - & 01 & - & - & 01 \\
\hline & BN & - & 05 & 01 & - & - & 02 & 01 & 01 & 10 \\
\hline & IHGB & 02 & 01 & - & - & - & 01 & - & - & 04 \\
\hline & 20 & 14 & 02 & 01 & 05 & 40 & 05 & 03 & 90 \\
\hline
\end{tabular}

Fonte: Dados da pesquisa.

Da Tabela 02 pode-se afirmar a importância do acesso aos acervos das instituições argentinas, maiores detentoras de documentos sobre a temática no recorte temporal. Soma-se a isto a política de acesso que não impõe barreiras para consulta e digitalização das obras por fotografia digital, já que a maioria é de domínio público. No Brasil, com exceção das instituições paranaenses, o acesso à documentação exige o conhecimento prévio das políticas e das possibilidades de acesso. No entanto, mesmo não tendo acesso a todas as obras catalogadas e não sendo permitido fotografar as consultadas, instituições como Arquivo Nacional e do Itamaraty guardam documentos importantes e que carecem novas pesquisas in loco.

As primeiras análises aos documentos se deram no intuito de constituir apontamentos iniciais às perguntas formuladas a partir dos objetivos específicos. Nesse sentido, os resultados do projeto mostram que a constituição documental sobre a paisagem obedeceu ao contexto histórico de conflito por domínio territorial. De certa forma, os dados corroboram com a afirmação de Karpinski (2017b) de que houve, neste período, um "conflito por domínio da paisagem". Segundo o mesmo autor, este conflito se deu no campo discursivo, onde o "arsenal" se constituiu de forma diplomática com Tratados e Laudos Arbitrais.

Dessa premissa, pode-se afirmar também que, para embasar esta discussão política internacional, uma rica documentação se constituiu no bojo deste contexto secular de defesa territorial e das contendas construídas e cultivadas entre os dois países. De acordo com Bandeira (2010), a rivalidade foi a principal característica das relações entre Brasil e Argentina desde suas independências no Século XIX, com alguns momentos de aproximação geralmente abatidos pelas Grandes Potências.

Essas rivalidades tiveram início com a expansão territorial brasileira e a disputa pelo Rio da Prata, via de acesso essencial ao interior do continente e às suas supostas fabulosas riquezas minerais. A luta pela 
posse da Colônia de Sacramento em frente à Buenos Aires e da Província Cisplatina, e a disputa por influência no Paraguai e Bolívia são episódios dessa rivalidade assim como a utopia argentina de reconstrução do Vice-Reinado do Rio da Prata, através de esquemas preferenciais de comércio entre suas antigas partes [...] (BANDEIRA, 2010, p. 27).

No que concerne especificamente às Cataratas do Iguaçu, a documentação catalogada e analisada possibilita a discussão sobre o objetivo específico "01" que é entender até que ponto as relações em torno do domínio pela paisagem das Cataratas do Iguaçu colaboraram para os acordos de limites e fronteiras entre Brasil e Argentina. Partindo da premissa de Karpinski (2011 e 2017b), são imprescindíveis para responder essa questão as informações disponíveis em Lista (1883), Ambrosetti (1892), Zeballos (1894), Queirel (1897), Argentina (1901), Nascimento (1903), Argentina (1910), Artigos (1910) e Silveira Netto (1914). Todos estes autores apresentam subsídios para os problemas relacionados ao chamado "quadrilátero" formado pelos rios Peperi Guaçu, Santo Antonio, Chapecó e Chopim. (KARPINSKI, GALLI-MATIAUDA, 2016).

Já no que concerne ao objetivo específico "02" que busca historiar as relações entre militares brasileiros e representantes do governo argentino em fins do Século XIX e início do XX na Colônia Militar da foz do Iguaçu, foi possível, até o momento, analisar um caso. Trata-se de um Projeto de Parque Nacional feito em 1888 pelo militar brasileiro Edmundo de Barros que, de acordo com Nascimento (1903), foi parar no Gabinete do Ministério da Agricultura da Argentina e subsidiou o projeto do Parque Nacional daquele país desenvolvido pelo famoso arquiteto e urbanista Charles de Thays. Informações sobre esta questão se encontra em Muricy (1897), Basaldua (1901), Thays (1902 e 1913) e Barros (1919). O aludido projeto de Edmundo de Barros não foi encontrado nesta pesquisa, apenas uma planta que lhe fazia parte e está disponível na Figura 3.

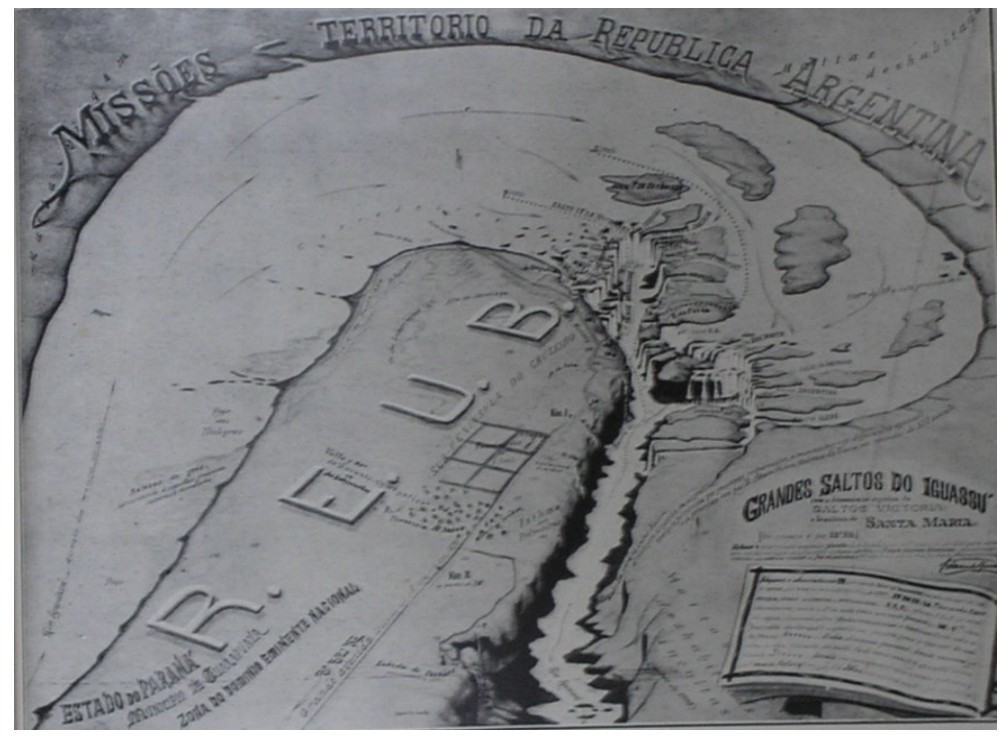

Figura 3: Planta dos Grandes Saltos do Iguaçu Fonte: Barros (1897).

No que se refere aos objetivos "03" - intercambiar documentos históricos - e "04" - formar um acervo digital sobre os objetos Parque Nacional e Cataratas do Iguaçu - pode-se dizer que este último foi plenamente atingido diante dos resultados 
apresentados acima. No entanto, não houve, até o momento, um intercâmbio de fontes, uma vez que apenas os pesquisadores brasileiros acessaram as fontes argentinas. Há que se ressaltar que nas instituições argentinas é maior a facilidade de acesso e menor a burocracia para as ações dos pesquisadores credenciados sobre as fontes de informação. Depois do credenciamento que se dá de forma distinta em cada instituição argentina, os pesquisadores foram autorizados a consultar todas as obras solicitadas e fotografar digitalmente os originais. Por isso, a intenção é continuar o tratamento do acervo digital recolhido no Brasil, a fim de disponibilizar aos pesquisadores argentinos interessados no tema.

\section{CONSIDERAÇÕES FINAIS}

Apresentou-se até aqui as atividades desenvolvidas pelo Projeto de Pesquisa Científica "A construção de uma 'maravilha': Brasil e Argentina e as disputas pela paisagem das Cataratas do Iguaçu (1850-1910)". A pesquisa consistiu em buscas de catálogos em sistemas de web de bibliotecas e arquivos no Brasil e na Argentina e de pesquisa in loco com o intuito de analisar e digitalizar, por meio de fotografia, o material existente. Dentre as 138 obras encontradas destacam-se os cartões postais, mapas e relatos de viagem, muitos destes com ilustrações e imagens advindas de fotografia, plantas, ilustrações e pinturas.

Com estes dados percebeu-se que existem muitos documentos sobre a temática e o período, uma vez que, até então, os estudos apontavam para a escassez de fontes. A catalogação e digitalização de 71 documentos históricos que perfizeram um total de 2091 imagens possibilitarão o acesso a inúmeras informações que certamente serão úteis na construção historiográfica da paisagem e da região em que está inserida.

Os primeiros resultados da análise das fontes apontam novidades no que se sabe até agora sobre o papel e a influência do mundo natural na construção dos limites e fronteiras dos Estados Nacionais, brasileiro e argentino. Além disso, se pode afirmar a continuidade da produção bibliográfica tanto sobre as relações históricas quanto da constituição documental em que elas se subsumem.

Diante do exposto, é possível afirmar que o projeto de pesquisa em tela, mesmo apresentando lacunas, cumpriu com seus objetivos e seus resultados poderão ser maiores daqui adiante. Um repositório digital está sendo pensado em parceria com o Programa de Pós-Graduação em Ciência da Informação e o contato dos alunos com as fontes poderá gerar projetos de TCC, mestrado e doutorado. A meta, a partir de agora, é inserir novos objetos de estudos dentro da temática de forma a abranger um escopo ainda maior nas discussões relacionadas à história das paisagens de fronteira.

\section{REFERÊNCIAS}

AGUIRRE, A. I.; MENDIETA, A. B.; CARETTA, M. N. (Coord.). Estudios regionales y de fronteras interiores. México, D. F: Universidad Autónoma de San Luis Potosí, Coordinación de Ciencias Sociales y Humanidades: Miguel Ángel Porrúa, 2008.

AMBROSETTI, J. B. Tercer Viaje a Misiones. Boletin del Instituto Geográfico Argentino. Buenos Aires, n. 9 al 12, 1892.

ARGENTINA. Comisión Argentina demarcadora de límites con el Brasil. Planos topográficos de las Islas del Río Uruguay y del Río Iguazú. [S.l.]: Talleres Gráficos de la Penitenciaría Nacional, 1901. 
La frontera argentino brasileña: estudios y demarcación general: 1887-1904. Buenos

Aires: Penitenciaría Nacional, 1910.

ARTIGOS declaratórios da demarcação de fronteiras entre os Estados Unidos do Brasil e a República Argentina. Rio de Janeiro, 1910. Disponível em:

< http://www.info.lncc.br/att1910.html>. Acesso em: 17 mar. 2015.

BALLERINI, A. Cascada del Iguazu. 1892. Óleo sobre tela sobre madeira, color. 34,5x 102cm. Museu Nacional de Belas Artes, Buenos Aires-Argentina. Disponível em:

<https://www.bellasartes.gob.ar/coleccion/obra/1846>. Acesso em: 09 jun. 2017.

BANDEIRA, L. A. M. Brasil, Argentina e Estados Unidos: conflito e integração na América do Sul (da Tríplice Aliança ao Mercosul). 3.ed.rev.amp. Rio de Janeiro: Civilização Brasileira, 2010.

BARROS, E. F. X. Partilha internacional dos grandes saltos do Iguassú. Boletim do Instituto Histórico e Geográphico Paranaense, Curitiba, a.2, v.2, p.9-25, 1919.

Planta Dos Grandes Saltos Do Iguaçu. 1897. In: NASCIMENTO, D. A hulha branca no Paraná. Curitiba: Centro de Letras do Paraná: Turnauer \& Machado, 1914. p.45.

BASALDÚA, F. Pasado, presente, provenir del territorio nacional de Misiones. La Plata [Prov. de Buenos Aires]: [s.n.], 1901.

CONSELHO NACIONAL DE ARQUIVOS - CONARQ. Recomendações para Digitalização de Documentos Arquivísticos Permanentes. Rio de Janeiro, 2010.

CONSELHO NACIONAL DE DESENVOLVIMENTO CIENTÍFICO E TECNOLÓGICO - CNPq. Bolsas. Brasília, 2006. Disponível em: <http://www.cnpq.br/web/guest/apresentacao13/>. Acesso em: 13 mar. 2017.

DELEUZE, G. Différence et répétition. Paris: PUF, 1968.

IFLA. Declaração de princípios internacionais de catalogação. Tradução de Lídia Alvarenga et al. [S.l.: s.n.], 2009. Disponível em: < https://www.ifla.org/files/assets/cataloguing/icp/icp_2009-pt.pdf>. Acesso em: 20 dez. 2017.

KARPINSKI, C. Navegação, cataratas e hidrelétrica: discursos e representações sobre o rio Iguaçu (1853-1969). Tese (Doutorado em História), Universidade Federal de Santa Catarina. Florianópolis, 2011.

A construção de uma "maravilha": Brasil e Argentina e as disputas pela paisagem das Cataratas do Iguaçu (1850-1910). Relatório Final do Projeto de Pesquisa Científica referente ao Processo 407613/2013-7, da Chamada 43/2013 - Ciências Humanas, Sociais e Sociais Aplicadas do CNPQ. Foz do Iguaçu, 2017a.

História do Rio Iguaçu: navegação, cataratas e hidrelétricas. Saarbrücken, Alemanha: NEA, 2017b.

.; GALLI-MATIAUDA, D. I. Paisagem e fronteira nas questões territoriais entre Brasil e Argentina (1860-1914). Revista NUPEM, Campo Mourão, v. 10, n. 17, p.72-85, maio/ago. 2017. Disponível em: <file:///C:/Users/Cezar/Downloads/321-49-911-1-10-20170609\%20(1).pdf> Acesso em: 16 ago. 2017.

LEVY, P. 0 que é o virtual. 2. ed. São Paulo: Ed. 34, 2011. 
LISTA, R. El territorio de las Misiones. Buenos Aires: Imprenta "La Universidad de J. N. Kligelfuss", 1883.

MASOTTA, C. Paisajes en las primeras postales fotográficas argentinas del S. XX. Buenos Aires: La Marca Editora, 2007.

MASSI, L.; QUEIROZ, S. L. Pesquisas sobre Iniciação Científica no Brasil: características do seu desenvolvimento nas universidades e contribuições para os graduandos. Revista Brasileira de Iniciação Científica. Itapetininga, v. 1, p. 1-27, 2014. Disponível em:

<https://itp.ifsp.edu.br/ojs/index.php/IC/article/view/12/423>. Acesso em: 20 dez. 2017.

MURICY, J. C. S. A' Foz do Iguassú: ligeira descripção de uma viagem feita de Guarapuava á Colonia da Foz do Iguassú em novembro de 1892. Curityba: Impressora Paranaense, 1896.

NASCIMENTO, D. V. Pela fronteira. Curytiba: Typ. d'A republica, 1903.

QUEIREL, Juan. Misiones. Buenos Aires: Taller Tipográfico de la Penitenciaría Nacional, 1897.

REPÚBLICA ARGENTINA. Feliz Año Nuevo: cataratas del Iguazú: República Argentina. [S.l.: s.n], 1901. 1 cartão-postal p\&b.

SCHAPOCHNIK, N. Cartões postais, álbuns de família e ícones da intimidade. In. SEVCENKO, N.; NOVAIS, F A. História da vida privada no Brasil: República: da belle époque à era do rádio. São Paulo: Companhia das Letras, 2006. p.423-512.

SILVEIRA NETTO, M. A. Do guayra aos saltos do Iguassú. Coritiba: Typographia do Diário Official, 1914.

THAYS, C. La excursión de M. Thays al Iguazú. Caras y caretas. Buenos Aires, 06 de abril de 1902.

THAYS, C. Los bosques naturales de la Republica Argentina. Paris: Congreso Forestal Internacional de Paris, 1913. In: BERJMAN, S. (comp.). Carlos Thays: sus escritos sobre jardines y paisajes. Buenos Aires: Ciudad Argentina, 2002.

ZEBALLOS, Estanislao S. Alegato de la República Argentina sobre la Cuestión de Límites con el Brasil en el Territorio de Misiones. Washington, 1894. 